\title{
Circular economy in the construction sector: advancing environmental performance through systemic and holistic thinking
}

\author{
Magnus Sparrevik ${ }^{1,2} \mathbb{D} \cdot$ Luitzen de Boer $^{1} \cdot$ Ottar Michelsen ${ }^{1} \cdot$ Christofer Skaar $^{1} \cdot$ Haley Knudson $^{3} \cdot$ \\ Annik Magerholm Fet ${ }^{1,3}$
}

Accepted: 5 February 2021 / Published online: 23 February 2021

(c) The Author(s) 2021

\begin{abstract}
The construction sector is progressively becoming more circular by reducing waste, re-using building materials and adopting regenerative solutions for energy production and biodiversity protection. The implications of circularity on construction activities are complex and require the careful evaluation of impacts to select the appropriate path forward. Evaluations of circular solutions and their environmental effectiveness are often performed based on various types of life cycle-based impact assessments. This paper uses systemic thinking to map and evaluate different impact assessment methodologies and their implications for a shift to more circular solutions. The following systemic levels are used to group the methodologies: product (material life cycle declarations and building assessments), organisation (certification and management schemes) and system (policies, standards and regulations). The results confirm that circular economy is integrated at all levels. However, development and structure are not coordinated or governed unidirectionally, but rather occur simultaneously at different levels. This recursive structure is positive if the methods are applied in the correct context, thus providing both autonomy and cohesion in decision making. Methods at lower systemic levels may then improve production processes and stimulate the market to create circular and innovative building solutions, whereas methods at higher systemic levels can be used, for example, by real estate builders, trade organisations and governments to create incentives for circular development and innovation in a broader perspective. Use of the performance methods correctly within an actor network is therefore crucial for successful and effective implementation of circular economy in the construction sector.
\end{abstract}

Keywords Circular economy $\cdot$ Construction sector $\cdot$ Systemic level thinking

\section{Introduction}

Circular economy $(\mathrm{CE})$ is becoming well known as a key concept for managing natural and technical resources towards a more sustainable society (Geissdoerfer et al. 2017). The construction sector is a resource intensive sector where the shift from linear to circular thinking may be important to reduce impacts and save resources worldwide

Magnus Sparrevik

magnus.sparrevik@ntnu.no

1 Department of Industrial Economics and Technology Management, Norwegian University of Science and Technology, Trondheim, Norway

2 Environmental Section, Norwegian Defence Estates Agency, Oslo, Norway

3 Department of International Business, Norwegian University of Science and Technology, Ålesund, Norway
(Eberhardt et al. 2020). In addition, the built environment has multiple functions of importance for many different people and should function over many years, even for decades. Choices made in this sector today are therefore likely to have widespread societal impacts for the foreseeable future.

Life cycle assessments (LCA) are often used to evaluate the environmental performance of circular solutions. Gallego-Schmid et al. (2020) point to the potential for emission reduction of $30-50 \%$ by closing resource loops, but conclude that systemic oriented barriers and lack of understanding hamper the realisation of this reduction in practice. Górecki et al. (2019) adds to the discussion by calling for a better understanding of CE horizontally, across topics and involved sectors, and vertically, from individual projects to international bodies.

The aim of this paper is therefore to better understand systemic enablers and constraints for CE implementation in the construction sector by focusing on environmental 
performance assessment methods. First, we investigate life cycle-based impact assessments for CE and present them across a model of systemic levels. The result is then used to discuss the interactions between the levels. Finally, we recommend how systemic and holistic thinking can aid strategy development for more effective implementation of $\mathrm{CE}$ in the construction sector.

\section{Theory and methods}

\subsection{Circular aspects for the construction sector}

The construction industry and built environment place significant pressure on the environment by being the largest consumers of natural resources, and use alone over a third of the energy produced annually worldwide (Munaro et al. 2020). In addition, the rising rate of urbanisation has an increasingly negative impact on biodiversity around the globe (McDonald et al. 2008). There is therefore a strong and evident need to reduce this impact by moving away from linear consumption patterns into more circular solutions, thus reducing the footprint of the built environment (Arora et al. 2020).

MacArthur (2013) defines three main principles relevant for circularity, and applicable to the construction sector, Fig. 1. Designing out waste and pollution, entails focussing on the embedded emissions from materials and resources connected to the building. Through design and careful consideration of the materials used, less resource intensive construction methods and re-use of the subsequent waste from building demolition, can reduce lifetime greenhouse gas (GHG) emissions. Hazardous chemicals in selected materials can be avoided, thus increasing the performance of the building and possibilities of further reuse. The principle of keeping products and materials in use is widely discussed in building design since there is substantial variation in the replacement rates of building components during use (Brand 1995), and since many building components have a lifetime expectancy that exceeds the lifetime of the building. For example, Munaro et al. (2020) found that approximately $40 \%$ of all literature about $\mathrm{CE}$ and the built environment deals with the reuse and recycling of materials. Circularity is also about the regeneration of natural systems. For a building, this means finding out how to minimise the use of external resources, such as energy and water, or even how to become a net producer of energy through localised energy production. It is also linked to protecting biodiversity by using surroundings or roof spaces for natural vegetation and stormwater management. In addition, by avoiding settlements in vulnerable areas and by using renewable and sustainable materials, pressure on natural systems can be reduced.

\subsection{Systemic levels of environmental performance}

Circularity in the construction sector involves many different topics for consideration including energy sources and associated performance, product and material impact and

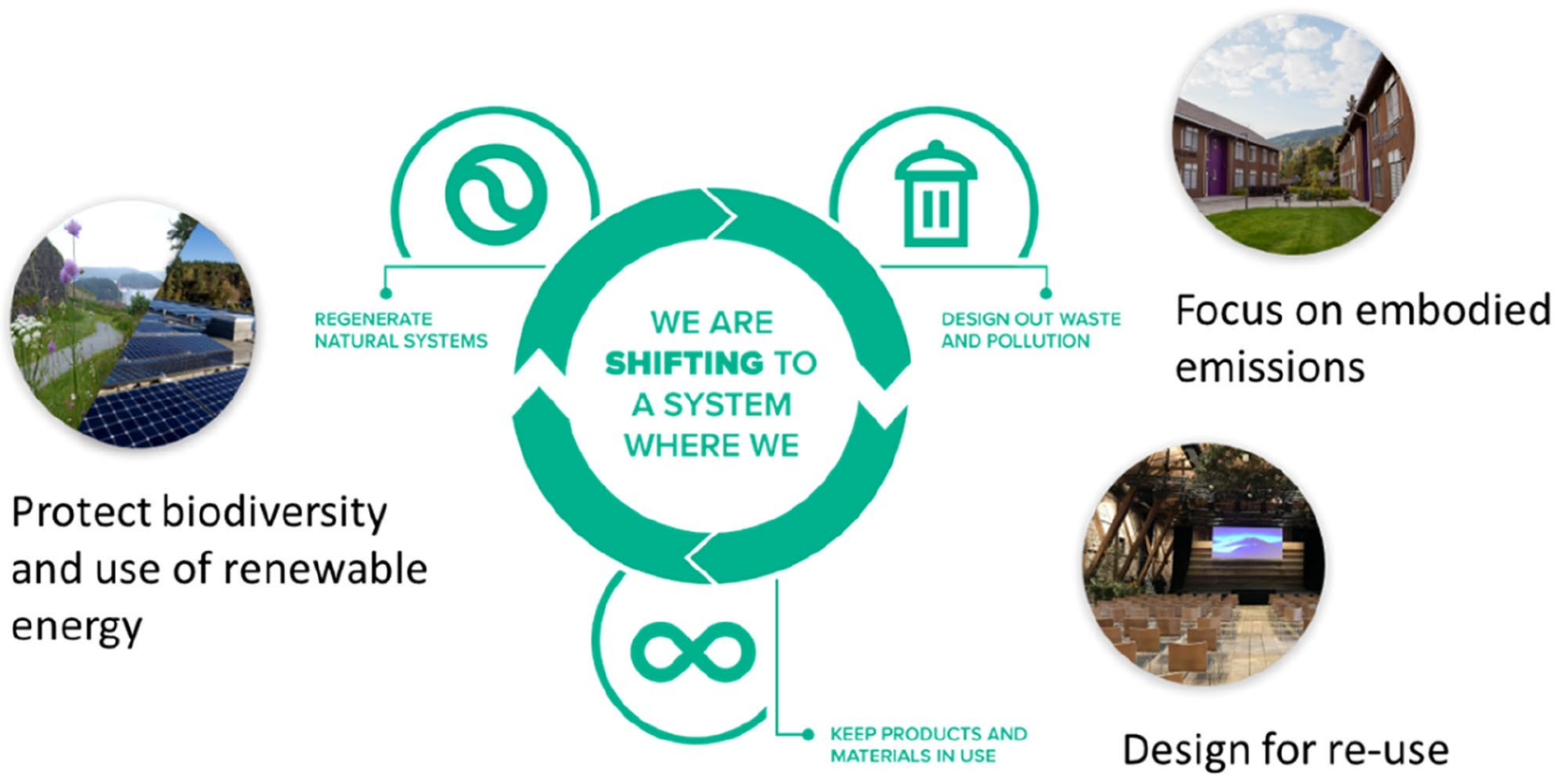

Fig. 1 Focus areas for circular economy in the construction sector. Adopted from principles described in MacArthur (2013). Pictures from the Norwegian Defence Estates Agency 
even the influence of nature conservation efforts. This multidisciplinarity is challenging and requires environmental performance tools with the ability to analyse environmental aspects and impacts during the lifetime of the building solution and that capture their contribution across different impact categories.

There are many LCA-based tools for analysing environmental performance in the building life cycle that can be applied at various stages of the building construction process. Use of these tools then provides valuable empirical results to improve circularity within the value-chain of the procurer and suppliers. In this paper, however, it is more valuable to investigate the role of these methods in different systemic dimensions than to investigate the performance itself.

According to Fet and Knudson (2021), tools for systematic implementation of sustainable solutions can be organized in a stepwise progression through four levels: (1) process improvement, (2) product improvement, (3) organisational improvement, and (4) (societal) system improvement. The methods may be separated across two dimensions; (i) in terms of the comprehensiveness of performance, and (ii) by the scope as defined by the complexity of impact. How one defines the content of each level depends on the point of entry, i.e., from which perspective one views the systemic levels.

Figure 2, shows how the model can be adapted to the construction sector with the most important assessment methods indicated at each level. Here, the point of entry is the building, seen itself as a product and placed in an organisational context. Each subsequent level is then defined according to this approach. From this perspective, we disregard the process level from the original model and assume that process improvements and related impact assessment methods are included as part of the suppliers' work to improve their products.

In the adapted model, the initial, product level connects to resource performance of the components of the building and the performance of the building itself. We therefore divide this level into two sub-levels: (a) building components and (b) the building itself.

For building components (level 2a), using materials with a high degree of recycled materials and produced without polluting materials ensures higher potential for circularity. The technical capacity and lifetime expectancy are also important considerations to keep products and materials in use for as long as possible.

The building itself (level 2b) logically connects to the circularity of the whole building. In this case, it is not only the embodied emissions from products and materials that count, but also the operational emissions and end of life that must be considered. In addition, building location affects travel patterns of residents and users of the building, thus causing emissions from the transportation of people, goods and services to the building. Since the lifetime of a building is long, ensuring circularity from the building perspective may require further optimisation between construction (including maintenance and renovation) and operational emissions.

The construction phase is typically divided between the two sub-levels. The impacts of the transportation of raw materials to the production site are often linked to the building components, and similarly with the transportation of products to the supplier. Impacts of transportation to the construction site and the resources associated with the
Fig. 2 Systematic change towards circular economy for the construction sector at different systemic levels. Adapted from Fet and Knudson (2021)

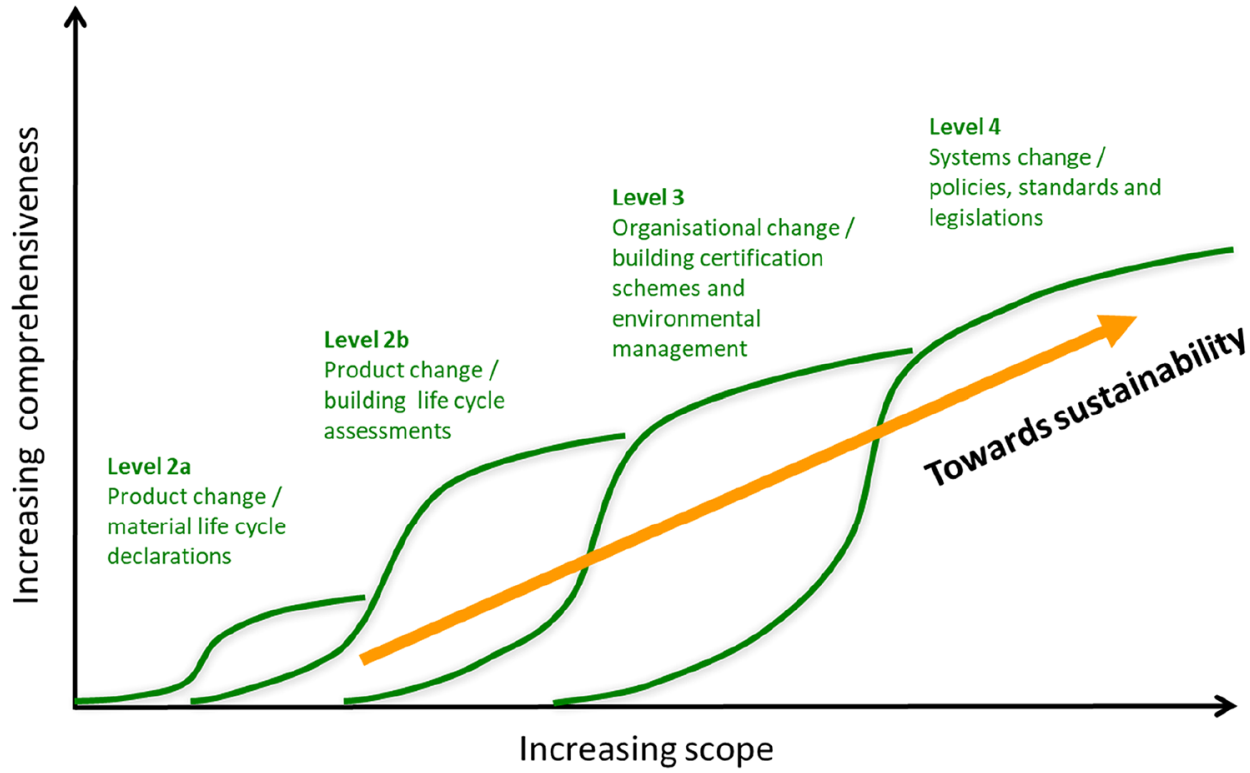


construction of the building, on the other hand, are often connected to the building itself.

According to the framework, the organisation level (level 3) relates to alignment across construction projects in a geographical or organisational context. Examples are the strategic decision making to follow certain protocols or certification arrangements that ensure buildings are constructed according to organisational objectives. This may create new internal markets based on altered requirements for construction activities, or result in new circular solutions, thus affecting the whole supply chain. However, this level also refers to the strategic decisions made by the entrepreneurs in the early design phase of new buildings and construction projects and the development of new or innovative circular concepts.

Finally, the system level (level 4) relates to larger initiatives, either cascading from pan-national regulations, such as EU regulations, national regulations and standards, or from various voluntary initiatives at the national or regional level, such as the development of the European framework for sustainable systems (EU 2020). Circularity in the system dimension has a broader impact than at other levels, as it allows for longer term predictability, thus creating the foundation for a circular market that may compete financially with established linear solutions.

\subsection{Research methodology}

Drawing on a systems and cybernetics approach, particularly the Viable System Model (VSM) by Beer (1972, 1995) and its application to sustainability as presented in Espinosa et al. (2008) and on actor-network theory (Latour 1987; Muniesa 2015) we analyse the main impact assessment methods used in the construction industry to achieve circular solutions. First, the impact assessment methods are selected and organised according to the systemic level model proposed by Fet and Knudson (2021), and possible enablers and constraints for $\mathrm{CE}$ at each level are discussed. Next, possible interactions between the systemic levels are analysed and discussed from a VSM perspective. Finally, these impacts and connections are considered in relation to their impact on management applications. Further research needs are also identified.

\section{Results and discussion}

\subsection{Identification and organisation of methods}

Requirements for CE solutions and the assessments of their environmental effectiveness are often based on the same foundation, i.e. the construction life cycle of the building. As summarised in Table 1, assessments are in practice tailored to the appropriate systemic level where they can act as both enablers and constraints for CE depending on the context.

For product (building component) impact assessments, the use of environmental product declarations (EPD) has gained popularity and EPDs are now widely available for most products and materials in the construction sector (Andersen et al. 2019; Burke et al. 2018; Passer et al. 2015). According to Fet et al. (2008) the purpose of an EPD is to create a standardised life cycle impact footprint of different product categories. The use of EPDs is transparent and allows the procurer to access information about the environmental impact of a material, product or service to be able to make well-informed decisions. An EPD does not evaluate, judge, or rate the products, but provides transparent information on the environmental impact. This makes it possible for the user of the EPD to make decisions in the relevant building context, and for the builder to select materials and products with the lowest environmental impact. Suppliers will thus be encouraged to use more recycled materials to reduce environmental impact, but also to improve their production processes through cleaner production technologies, lower energy use and the selection of more sustainable transportation services. In the long run this will enhance circularity. Comparisons should however be made carefully since not all life cycle stages are treated equally (Durão et al. 2020). This may result in a bias towards materials and products with low

Table 1 Overview of methodology for environmental impact assessments at different systemic levels and the possible enablers and constraints for circular solutions

\begin{tabular}{|c|c|c|c|}
\hline Level & Methodology & Possibly enabling & Possibly constraining \\
\hline Product (building components) & Material life cycle declarations & $\begin{array}{l}\text { Better performance at supplier } \\
\text { level and product improvements }\end{array}$ & $\begin{array}{l}\text { The ability to compare impacts } \\
\text { across areas and life cycle stages }\end{array}$ \\
\hline Product (building itself) & Building life cycle assessments & $\begin{array}{l}\text { Circular building design and solu- } \\
\text { tions }\end{array}$ & $\begin{array}{l}\text { Enhanced efficiency due to case-to- } \\
\text { case based solutions }\end{array}$ \\
\hline Organisational & $\begin{array}{l}\text { Building certification schemes and } \\
\text { environmental management }\end{array}$ & $\begin{array}{l}\text { Higher built environment standard } \\
\text { and better organisational perfor- } \\
\text { mance }\end{array}$ & $\begin{array}{l}\text { Unidirectional effect due to volun- } \\
\text { tariness and user driven ambition } \\
\text { levels }\end{array}$ \\
\hline System & Policies, standards and legislations & Broad scale systemic change & $\begin{array}{l}\text { Voluntary initiatives for innovative } \\
\text { solutions }\end{array}$ \\
\hline
\end{tabular}


emissions in the production stage without placing enough focus on the impact created in the use or end of life stages.

If we move from the analysis of each building component, or each subsystem, to the actual product in terms of the building, the scope becomes more comprehensive. There may be several pathways to increase circularity and there are trade-offs between different implementation areas. According to Arora et al. (2020) and Eberhardt et al. (2019), re-use of building materials will reduce environmental life cycle impacts from the building perspective, but the wider effect depends on the design choices and local conditions that will produce varied results (Benachio et al. 2020). For example, extensive refurbishment to enhance energy performance may be counterproductive due to the technical lifetime of building materials, especially if renewable energy is used. Other circular topics that can be compared at the building level are the creation of multipurpose buildings to reduce the need for new construction projects, and the utilisation of surroundings for biodiversity or enhancing regenerative solutions for technical installations. LCA or GHG calculations at this level quickly become cumbersome and data intense, and thus create a need for digitised interactive solutions to standardise the calculations (Petrovic et al. 2019). However, since circular solutions on the building level are primarily developed from case to case, enhancing efficiency is difficult, making solutions more costly and difficult to reproduce.

The need for streamlining and related impact methods at the organisational level is therefore widely discussed in literature (Eberhardt et al. 2020; Gallego-Schmid et al. 2020; López Ruiz et al. 2020). Even though assessments of life cycle impacts can be conducted from an organisational perspective (Martínez-Blanco and Finkbeiner 2018), it is more common to use functional or organisational targets provided in certifiable management systems to define the performance level of circular solutions. In building certification schemes (e.g., LEED, BREEAM or similar), the proposed project is scored against specific predefined targets covering a variety of topics valid for the construction and use phases of the building. Building certification includes a broad sustainability perspective, and typical circularity themes such as energy, material use and water efficiency are normally focused on heavily in the targets (Awadh 2017). Introduction of environmental management (EM) will therefore require the organisation to identify significant environmental aspects and to set objectives and targets accordingly. For a real estate builder, this will most certainly involve objectives to improve circularity (Brem et al. 2020). Even though building certification and certified EM provide possibilities to benchmark environmental status at the organisational level (Cole and Valdebenito 2013), these systems are still voluntary and allow the user to set sometimes low ambitions for performance. In addition, the various schemes emphasise sustainability aspects differently, and the content and weighting are not unified or coordinated in their development (Mattoni et al. 2018).

Finally, at the system level we have a broad variety of policy, standards and regulation with expected systemic effects. The various EU policies on resource policy direct the construction sector towards circularity but depend on national instruments, standards and priorities to be effective (Domenech and Bahn-Walkowiak 2019). Energy, nature conservation and technical design are often well described in regulatory frameworks and have been part of CE for the built environment for a long time (Mulhall and Braungart 2010). More innovative activities, such as the introduction of emission free construction sites, are difficult to regulate without being successfully demonstrated at the lower building level (Fufa et al. 2018). In this case, developments based on voluntary organisational commitments can be more effective enablers. The example of emission free construction sites is to a significant extent the result of such an organisational white paper developed by the Norwegian Government for the construction sector, pushing the market for innovation.

\subsection{Systemic interactions}

By examining the different impact methods from a systemic perspective, we confirm the model by Fet and Knudson (2021) and show the relation between product (building components and the building itself), organisational and system levels for the development of circular solutions. We further see that CE is integrated at all levels, but that development has been far from coordinated or governed from an overarching perspective. It has been natural to look at products and the improvement of manufacturing processes first (Kjaerheim 2005), since product LCA, based on attributional LCA, has been around for decades (Bjørn et al. 2018). LCA on the building level and building certification schemes have been in use since the 1990's, but have recently increased in popularity, in connection with legislation, white papers and innovative strategies on the strategic level (Brem et al. 2020; Ismaeel 2019; Shan and Hwang 2018). In the Nordic countries, legislation is presently expanding from covering only energy requirements in the use phase, to all GHG emissions from the life cycle perspective (Kuittinen and Häkkinen 2020; Moschetti et al. 2019).

In the sense that methodology on the system level directly affects how methods on the lower levels are used, we see no unidirectional response. Instead, development of methods occurs simultaneously, which may be both positive and negative for the further development of circular solutions. On the one hand, this flexibility has advanced the market by allowing for successful implementation wherever applicable, thus creating many strong examples of pilot projects and innovation for circularity (Brem et al. 2020; Burke et al. 2018; Fufa et al. 2018). On the other hand, Kanters (2020) 
describes a complex value-chain for circular building projects and explains that the lack of systemic intervention may limit implementation to only the most proactive clients, especially if profit cannot be demonstrated. There is also the risk of long feedback periods from the higher systemic levels to the lower due to uncertainty and phasing-in of new methods, e.g., that the product requirements used in buildings were used first to document performance, before moving on to the more comprehensive evaluation and comparison of the performance of products.

Development of methods at the product level will continue to affect methods at higher systemic levels. Conversely, changes at the system level will set new requirements and subsequently affect assessment methods at the lower systemic levels. Instead of a stepwise development, therefore, we will see more interactions within the network, where interplay between actors impacts the assessment methods simultaneously. As a result, we can expect that even as methods at different systemic levels interact, the development of assessment methods for circular solutions will continue increasingly and simultaneously at all levels.

The suggested intricate dynamics of the interactions between the levels - and hence the methods applied at each level—can be further analysed and corroborated by mapping the systemic model (Fet and Knudson 2021) onto the VSM (Beer 1972, 1995), and more specifically through their application to sustainability as laid out by Espinosa et al. (2008).

First, from a VSM perspective, the existence of different systemic levels in the model on which different methods are applied, is a necessity following from the essential property of recursiveness of any viable network, i.e. any viable network contains - and is itself contained—by other viable networks. Construction projects consist of smaller subprojects and are themselves contained by larger organisations, for example, a municipality which again relates to regional and national governance structures, which are in turn contained in structures at an international level. This recursiveness allows each network to maintain viability by focusing on "only" part of the proliferating variety in its environment. Together, the viable networks at the different recursion levels can absorb the immense variety in the larger environment (Ashby 1961). However, as pointed out by Espinosa et al. (2008) when addressing sustainability, the recursive structure should be able to provide both autonomy and cohesion. Local projects and CE initiatives must therefore have sufficient autonomy to address the specific challenges in their local environment, whilst $\mathrm{CE}$ actions at higher recursion levels must provide a sense of direction and cohesion among individual actions to secure sufficient joint impact. Hence, the set of assessment methods applied at the different levels should exhibit both looseness and a certain stability in its core.
In effect, recursiveness then also logically defies a strict top-down or hierarchical approach when striving for more sustainable solutions (Espinosa et al. 2008). Interaction between viable networks throughout their nested, recursive structure will have to be both "upwards" and "downwards," as we also see in the interaction patterns between the assessment methods for $\mathrm{CE}$ at the different levels.

Finally, we draw attention to Espinosa et al. (2008) who emphasize the importance of what they call the "structural coupling" between each viable network and its niche in the environment, i.e. the specific part or subset of the "larger" environment that the network really considers and cognitively is aware of. For our purpose, this implies that at each level of recursion, for an initiative or project aimed at CE to be effective, its effort will be focused on a limited set of actors and processes in the (local) environment, which we may call " $C E$-niches." Even though assessments methods, e.g. LCA, may be highly standardised in terms of their technical design, their ability to cause actual change depends on how well their application is embedded in the particular CE-niche under consideration. This again underlines the importance of the local autonomy needed to connect the methods-although generic by design - to the specifics of the local project or effort.

\subsection{Management implications}

The paper highlights several findings with management implications for advancing CE in the construction industry, thus relating to the scope and comprehensiveness and scope of decision making in relation to the proposed systemic model.

The first finding emphasises the importance of addressing environmental performance within the correct scope to be able to make well balanced and sustainable decisions (Labonnote et al. 2017). Each decision needs to be both autonomous and well-functioning within the corresponding CE-niche, while at the same time being cohesive enough to enact recursively into other systemic niches. For example, embodied material related emissions often dominate GHG emissions in a building life cycle (Wiik et al. 2018), thus suggesting a heavy focus on process improvements at the supplier level. This is inherently robust and positive since it pushes the market to be innovative and develop more circular solutions. However, from a broader perspective, decarbonisation of the energy supply may be a more effective enabler for $\mathrm{CE}$ solutions than the material focus (also in terms of cost-efficiency). Depending on the energy situation in each country and expected life cycle cost savings (Ibn-Mohammed 2017), energy solutions may therefore be more prioritised than embodied material emissions when looking at higher systemic levels. The recursive structure will encompass $\mathrm{CE}$ in terms of both 
materials and energy but allows for different prioritisation depending on the context in which the decision is made.

The second finding stresses the importance of finding the appropriate comprehensiveness for addressing CE in buildings. As Pomponi and Moncaster (2017) point out, circular building design encompasses not only environmental and technical aspects but also governmental and behavioural dimensions. These are best developed through organisational tools such as building certification schemes, or even by regulatory work at the system level. However, high level scores in certification schemes and more stringent regulations are not possible without proper technical solutions at the product level or a functioning market with the ability to supply solutions. Stringent regulations are not possible without proper technical solutions at the product level or a functioning market with the ability to supply solutions. Successful implementation of building certification can therefore create both the perceived benefits of living for users and the business opportunities for the market. These are decisions that have a broader impact than only the environmental performance of the single building, and therefore require an organisational focus to be effective.

\subsection{Need for further research}

Implementing systemic level thinking in $\mathrm{CE}$ for the construction sector is important for addressing management implications and for further research. Several literature surveys have been conducted on $\mathrm{CE}$ and the construction sector (Benachio et al. 2020; Eberhardt et al. 2020; Munaro et al. 2020). They document growing research efforts, but also point to gaps and barriers to successful implementation. Most evident is the lack of research on the organisational and system levels, i.e. how research on the building level can be transferred into increased standardisation and better market mechanisms. In addition, it is important not to limit circularity only to the re-use and recycling of construction materials, but to keep the broad focus of circular principles in mind (MacArthur 2013). Further, interdisciplinary research focus is needed at all viable and recursive systemic levels. When this is combined with the actor perspective, involving network actors from the micro-scale (project focus) to macro-scale (city or regional focus), the complexity increases as discussed by Gallego-Schmid et al. (2020). In addition to needing to address life cycle impacts across a variety of aspects, this will require dynamic impact models that take technological development and innovation into consideration. It therefore may not be fruitful to shove all these aspects into one single type of requirement or assessment method, but instead to allow for use of different methods applied at the correct systemic level.

\section{Conclusion}

$\mathrm{CE}$ has become an appealing concept to frame the conversion from linear use of resources and materials into circular applications where re-use may also be economically profitable (Korhonen et al. 2018). In the construction sector, reduction of waste and re-use of building materials through circular solutions have been especially in focus (López Ruiz et al. 2020), but the concept may be adapted for other regenerative systems such as energy production and nature conservation as well (Mulhall and Braungart 2010).

In this paper, we have described several methods for assessing environmental performance for the built environment, most of them using a life cycle perspective that follows the distinct phases of a building life cycle; construction, use and end of life. Often, methods are interwoven and overlapping and may create confusion around the effect of enhancing the development of circular solutions (Hossain et al. 2020).

From a systemic perspective it becomes clearer that the methods are working recursively in actor-networks, and therefore affect society and the market differently depending on the systemic level. Methods at lower systemic levels, such as the use of EPDs and building LCAs, may stimulate the market to create circular solutions, while methods at higher systemic levels, such as building certification, environmental management systems and regulations, are used by real estate builders, trade organisations and governments to create incentives for circular development and innovation. When assessing environmental performance for $\mathrm{CE}$ in the construction industry, a recursive structure that allows for both autonomy and cohesion in decision making becomes crucial for successful and effective implementation.

Funding Open access funding provided by NTNU Norwegian University of Science and Technology (incl St. Olavs Hospital - Trondheim University Hospital).

Open Access This article is licensed under a Creative Commons Attribution 4.0 International License, which permits use, sharing, adaptation, distribution and reproduction in any medium or format, as long as you give appropriate credit to the original author(s) and the source, provide a link to the Creative Commons licence, and indicate if changes were made. The images or other third party material in this article are included in the article's Creative Commons licence, unless indicated otherwise in a credit line to the material. If material is not included in the article's Creative Commons licence and your intended use is not permitted by statutory regulation or exceeds the permitted use, you will need to obtain permission directly from the copyright holder. To view a copy of this licence, visit http://creativecommons.org/licenses/by/4.0/. 


\section{References}

Andersen SC, Larsen HF, Raffnsøe L, Melvang C (2019) Environmental product declarations (EPDs) as a competitive parameter within sustainable buildings and building materials. IOP Conf Ser: Earth Environ Sci 323:012145. https://doi.org/10.1088/17551315/323/1/012145

Arora M, Raspall F, Cheah L, Silva A (2020) Buildings and the circular economy: estimating urban mining, recovery and reuse potential of building components. Resour Conserv Recycl 154:104581. https://doi.org/10.1016/j.resconrec.2019.104581

Ashby WR (1961) An introduction to cybernetics. Chapman \& Hall Ltd, New York

Awadh O (2017) Sustainability and green building rating systems: LEED, BREEAM, GSAS and Estidama critical analysis. J Build Eng 11:25-29. https://doi.org/10.1016/j.jobe.2017.03.010

Beer S $(1972,1995)$ Brain of the firm: a development in management cybernetics. Herder and Herder, Freiburg im Breisgau

Benachio GLF, Freitas MdCD, Tavares SF (2020) Circular economy in the construction industry: a systematic literature review. J Clean Prod 260:121046. https://doi.org/10.1016/j.jclepro.2020.121046

Bjørn A, Owsianiak M, Molin C, Hauschild MZ (2018) LCA history. In: Hauschild MZ, Rosenbaum RK, Olsen SI (eds) Life cycle assessment: theory and practice. Springer, Cham, pp 17-30. https ://doi.org/10.1007/978-3-319-56475-3_3

Brand S (1995) How buildings learn: what happens after they're built. Penguin, London

Brem A, Cusack DO, Adrita MM, O'Sullivan DT, Bruton K (2020) How do companies certified to ISO 50001 and ISO 14001 perform in LEED and BREEAM assessments? Energy Effic 13:751. https ://doi.org/10.1007/s12053-020-09864-6

Burke RD, Parrish K, Asmar ME (2018) Environmental product declarations: use in the architectural and engineering design process to support sustainable construction. J Constr Eng Manage 144:04018026. https://doi.org/10.1061/(ASCE)CO.19437862.0001481

Cole RJ, Valdebenito JM (2013) The importation of building environmental certification systems: international usages of BREEAM and LEED. Build Res Inf 41:662-676. https://doi. org/10.1080/09613218.2013.802115

Domenech T, Bahn-Walkowiak B (2019) Transition towards a resource efficient circular economy in Europe: policy lessons from the EU and the Member States. Ecol Econ 155:7-19. https://doi. org/10.1016/j.ecolecon.2017.11.001

Durão V, Silvestre JD, Mateus R, de Brito J (2020) Assessment and communication of the environmental performance of construction products in Europe: comparison between PEF and EN 15804 compliant EPD schemes. Resour Conserv Recycl 156:104703. https://doi.org/10.1016/j.resconrec.2020.104703

Eberhardt LCM, Birgisdóttir H, Birkved M (2019) Life cycle assessment of a Danish office building designed for disassembly. Build Res Inf 47:666-680. https://doi.org/10.1080/09613 218.2018.1517458

Eberhardt LCM, Birkved M, Birgisdottir H (2020) Building design and construction strategies for a circular economy. Archit Eng Des Manage. https://doi.org/10.1080/17452007.2020.1781588

Espinosa A, Harnden R, Walker J (2008) A complexity approach to sustainability—Stafford Beer revisited. Eur J Oper Res 187:636651. https://doi.org/10.1016/j.ejor.2007.03.023

EU (2020) Level(s) - The European framework for sustainable buildings. https://ec.europa.eu/environment/eussd/buildings.htm. Accessed 11 Nov 2020

Fet A, Knudson H (2021) Transdisciplinarity in sustainability management. In: Keitsch MMV, Vermeulen WJ (eds) Transdisciplinarity for sustainability: aligning diverse practices. Routledge, London, pp 93-117

Fet A, Skaar C, Michelsen O (2008) Product category rules and environmental product declarations as tools to promote sustainable products: experiences from a case study of furniture production. Clean Technol Environ Policy 11:201-207. https://doi. org/10.1007/s10098-008-0163-6

Fufa SM, Wiik MK, Andressen I (2018) Estimated and actual construction inventory data in embodied greenhouse gas emission calculations for a norwegian zero emission building (ZEB) construction site. In: Kaparaju P, Howlett RJ, Littlewood J, Ekanyake C, Vlacic L (eds) Sustainability in energy and buildings. Springer, Cham, pp 138-147

Gallego-Schmid A, Chen H-M, Sharmina M, Mendoza JMF (2020) Links between circular economy and climate change mitigation in the built environment. J Clean Prod 260:121115. https://doi. org/10.1016/j.jclepro.2020.121115

Geissdoerfer M, Savaget P, Bocken NMP, Hultink EJ (2017) The circular economy - a new sustainability paradigm? J Clean Prod 143:757-768. https://doi.org/10.1016/j.jclepro.2016.12.048

Górecki J, Núñez-Cacho P, Corpas-Iglesias FA, Molina V (2019) How to convince players in construction market? Strategies for effective implementation of circular economy in construction sector. Cogent Eng 6:1690760. https://doi.org/10.1080/23311 916.2019.1690760

Hossain MU, Ng ST, Antwi-Afari P, Amor B (2020) Circular economy and the construction industry: existing trends, challenges and prospective framework for sustainable construction. Renew Sustain Energy Rev 130:109948. https://doi.org/10.1016/j. rser.2020.109948

Ibn-Mohammed T (2017) Application of mixed-mode research paradigms to the building sector: a review and case study towards decarbonising the built and natural environment. Sustain Cities Soc 35:692-714. https://doi.org/10.1016/j.scs.2017.09.027

Ismaeel WSE (2019) Drawing the operating mechanisms of green building rating systems. J Clean Prod 213:599-609. https://doi. org/10.1016/j.jclepro.2018.12.115

Kanters J (2020) Circular building design: an analysis of barriers and drivers for a circular building. Sect Build 10:77. https://doi. org/10.3390/buildings10040077

Kjaerheim G (2005) Cleaner production and sustainability. J Clean Prod 13:329-339. https://doi.org/10.1016/S0959-6526(03)00119 $-7$

Korhonen J, Honkasalo A, Seppälä J (2018) Circular economy: the concept and its limitations. Ecol Econ 143:37-46. https://doi. org/10.1016/j.ecolecon.2017.06.041

Kuittinen M, Häkkinen T (2020) Reduced carbon footprints of buildings: new Finnish standards and assessments. Build Cities 1:182

Labonnote N, Skaar C, Rüther P (2017) The potential of decision support systems for more sustainable and intelligent constructions: a short overview. Procedia Manuf 12:33-41. https://doi. org/10.1016/j.promfg.2017.08.006

Latour B (1987) Science in action: how to follow scientists and engineers through society. Harvard University Press, Cambridge

López Ruiz LA, Roca Ramón X, Gassó Domingo S (2020) The circular economy in the construction and demolition waste sector-a review and an integrative model approach. J Clean Prod 248:119238. https://doi.org/10.1016/j.jclepro.2019.119238

MacArthur E (2013) Towards the circular economy. J Ind Ecol 2:23-44

Martínez-Blanco J, Finkbeiner M (2018) Organisational LCA. In: Hauschild MZ, Rosenbaum RK, Olsen SI (eds) Life cycle assessment theory and practice. Springer, Cham, pp 481-498. https:// doi.org/10.1007/978-3-319-56475-3_20

Mattoni B, Guattari C, Evangelisti L, Bisegna F, Gori P, Asdrubali F (2018) Critical review and methodological approach to evaluate 
the differences among international green building rating tools. Renew Sustain Energy Rev 82:950-960. https://doi.org/10.1016/j. rser.2017.09.105

McDonald RI, Kareiva P, Forman RTT (2008) The implications of current and future urbanization for global protected areas and biodiversity conservation. Biol Cons 141:1695-1703. https://doi. org/10.1016/j.biocon.2008.04.025

Moschetti R, Brattebø H, Sparrevik M (2019) Exploring the pathway from zero-energy to zero-emission building solutions: a case study of a Norwegian office building. Energy Build 188-189:84-97. https://doi.org/10.1016/j.enbuild.2019.01.047

Mulhall D, Braungart M (2010) Cradle to cradle criteria for the built environment. EKONOMIAZ Rev vasca de Econ 75:182-193

Munaro MR, Tavares SF, Bragança L (2020) Towards circular and more sustainable buildings: a systematic literature review on the circular economy in the built environment. J Clean Prod 260:121134. https://doi.org/10.1016/j.jclepro.2020.121134

Muniesa F (2015) Actor-network theory. In: Wright JD (ed) International encyclopedia of the social \& behavioral sciences, 2 nd edn. Elsevier, Oxford, pp 80-84. https://doi.org/10.1016/B978-0-08097086-8.85001-1
Passer A et al (2015) Environmental product declarations entering the building sector: critical reflections based on 5 to 10 years experience in different European countries. Int J Life Cycl Assess 20:1199-1212. https://doi.org/10.1007/s11367-015-0926-3

Petrovic B, Myhren JA, Zhang X, Wallhagen M, Eriksson O (2019) Life cycle assessment of building materials for a single-family house in Sweden. Energy Procedia 158:3547-3552. https://doi. org/10.1016/j.egypro.2019.01.913

Pomponi F, Moncaster A (2017) Circular economy for the built environment: a research framework. J Clean Prod 143:710-718. https ://doi.org/10.1016/j.jclepro.2016.12.055

Shan M, Hwang B-g (2018) Green building rating systems: global reviews of practices and research efforts. Sustain Cities Soc 39:172-180. https://doi.org/10.1016/j.scs.2018.02.034

Wiik MK, Fufa SM, Kristjansdottir T, Andresen I (2018) Lessons learnt from embodied GHG emission calculations in zero emission buildings (ZEBs) from the Norwegian ZEB research centre. Energy Build 165:25-34. https://doi.org/10.1016/j.enbui ld.2018.01.025 